\title{
Mức sẵn lòng chi trả dịch vụ môi trường rừng ngập mặn tại Việt Nam Trường hợp nghiên cứu tại Hải Phòng
}

Phạm Thu Thủy', Nguyễn Đình Tiến², Nguyễn Đức Hậu², Trần Yến Ly², Nguyễn Thi Thu Quỳnh², Nguyễn Thủy Anh', Hoàng Tuấn Long', Đào Thị Linh Chi'

\section{Thông điệp chính}

- Đa số tàu cá và tàu du lịch được phỏng vấn sẵn sàng chi trả để bảo vệ và phát triển rừng ngập mặn bởi theo họ rừng ngập mặn cung cấp các dịch vụ chính như vẻ đẹp cảnh quan, bảo vệ đê điều, và bảo tôn đa dạng sinh học

- Trung bình, tàu du lịch sẵn sàng trả 0.45 triệu đồng/năm và tàu cá sẵn sàng trả 0.58 triệu đồng/năm. Tuy nhiên, nếu chúng ta phân tích sự sẵn lòng chi trả bằng mô hình logit, thì sự sẵn sàng chi trả trung bình của tàu cá là 1.376 triệu đông

- Mức độ sẵn lòng chi trả của tàu cá và tàu du lịch phụ thuộc vào thu nhập hàng năm, chi phí hoạt động của họ và kích cỡ tàu sở hữu

- Câu hỏi ai sẽ thu phí và cách quản lý quỹ cũng đã được thảo luận với các bên liên quan tại địa phương. Theo họ, việc thu tiền dịch vụ môi trường rừng (DVMTR) có thể thông qua ban quản lí cảng, bộ đội biên phòng hoặc chi cục thủy sản. Tuy nhiên, hầu hết những người được phỏng vấn đều cho rằng bộ đội biên phòng phù hợp hơn vì hiện bộ đội biên phòng đã có kinh nghiệm hỗ trợ chính quyền địa phương thu thuế, phí môi trường và quản lý trực tiếp tàu thuyền .

- Cần có các nghiên cứu ở các địa điểm khác tại Việt Nam và với các nhóm cung cấp dịch vụ môi trường khác để xác nhận tính khả thi của chương trình này.

\section{Giới thiệu}

Việt Nam đã xây dựng và thực hiện Chính sách Chi trả dịch vụ môi trường rừng tại Việt Nam từ năm 2008 (PFES). Trong nhiều thập thập kỉ qua, nhiều nghiên cứu đã cho thấy sự sụt giảm mạnh về diện tích rừng ngập mặn và do vậy một trong những ưu tiên của PFES là xây dựng cơ chế chi trả môi trường rừng (Chính Phủ Việt Nam 2010). Các học giả trong nước và quốc tế đã chỉ ra nhiều dịch vụ môi trường (DVMTR) đa dạng do rừng ngập mặn cung cấp, đặc biệt trong

1 Tổ chức nghiên cứu lâm nghiệp quốc tế (CIFOR)

2 Trường Đại học Kinh tế, Đại học Quốc gia Hà Nội việc giải quyết các tác động của biến đổi khí hậu. Tuy nhiên, cho đến nay chi trả DVMTR ngập mặn ở Việt Nam mới chủ yếu tập trung vào các dịch vụ nuôi trồng thủy sản và cung ứng bãi đẻ trong khi điều này gặp nhiều khó khăn khi triển khai trong thực tế (Pham và các cộng sự 2020). Việc mở rộng các chương trình chi trả DVMTR cho các dịch vụ môi trường rừng ngập mặn hiện đang được Quỹ Bảo vệ và Phát triển rừng Việt Nam (VNFF) xem xét. Chính phủ Việt Nam cũng yêu cầu thêm nhiều nghiên cứu để tìm hiểu thêm các dịch vụ môi trường mà rừng ngập mặn cung cấp cũng như những người sử dụng rừng ngập mặn sẵn sàng trả tiền để bảo vệ rừng ngập mặn tại Việt Nam (VNFF 2020). Tài liệu này thảo luận về cả các dịch vụ môi 
trường mà rừng ngập mặn hiện đang cung cấp cho người sử dụng dịch vụ môi trường ở Hải Phòng và mức độ sẵn lòng chi trả của họ cho các DVMTR này.

Phạm và cộng sự (2020) đã xác định 8 dịch vụ môi trường rừng ngập mặn chính ở Việt Nam và tại Hải Phòng bao gồm: 1) Dịch vụ hấp thụ, lưu trữ, bể chứa các-bon; (2) Dịch vụ giảm bồi lắng và bùn thải; 3) Dịch vụ chống xói lở bờ biển; 4) Dịch vụ Chắn sóng; 5) Dịch vụ cung ứng nước sạch, lọc kim loại nặng và chất ô nhiễm; 6) Dịch vụ cung ứng bãi đẻ; 7) Dịch vụ vẻ đẹp cảnh quan; 8) Dịch vụ cung cấp nguyên liệu thực phẩm. Tác giả cũng đã xác định được 20 nhóm người mua tiềm năng có thể chi trả cho các dịch vụ môi trường rừng ngập mặn ở Hải Phòng. Nhóm người mua này bao gồm: các công ty tập trung vào nạo vét, khai thác cát, nước sạch, năng lượng, ngân hàng, dầu khí, giải trí, du lịch, đóng tàu, vận tải hàng không và sản xuất nông, lâm, thủy sản; cảng cá và cảng biển; những bên tham gia vào khu kinh tế ven biển; các ngành công nghiệp tập trung vào khai thác và luyện kim, giao thông vận tải và nhiệt điện; các nhóm quản lý đê điều; và các cộng đồng dân cư. Tuy nhiên, không phải tất cả các dịch vụ môi trường mà rừng ngập mặn cung cấp đều được người sử dụng dịch vụ môi trường thừa nhận và do đó, họ có thể không muốn trả tiền cho các dịch vụ này. Vì vậy, điều quan trọng là phải hiểu được thị trường cho mỗi dịch vụ môi trường rừng ngập mặn cung cấp mà người sử dụng dịch vụ môi trường sẵn lòng chi trả.

Nghiên cứu tóm tắt này tập trung vào nhận thức của ba bên sử dụng dịch vụ môi trường ở Hải Phòng bao gồm: tàu đánh cá, các nhà quản lý cảng biển, tàu thuyền du lịch về các dịch vụ môi trường rừng ngập mặn họ sử dụng và sự sẵn lòngđể trả tiền cho dịch vụ đó. Nghiên cứu này là sản phẩm hợp tác giữa Trung tâm Nghiên cứu Lâm nghiệp Quốc tế và Đại học Quốc gia Hà Nội và được kỳ vọng sẽ cung cấp thông tin đầu vào cho VNFF trong việc xây dựng kế hoạch chi trả dịch vụ môi trường rừng ngập mặn tại Việt Nam trong tương lai.

\section{Phương pháp}

Để tiến hành nghiên cứu, chúng tôi thu thập thông tin thông qua rà soát lại hành lang pháp lí và chính

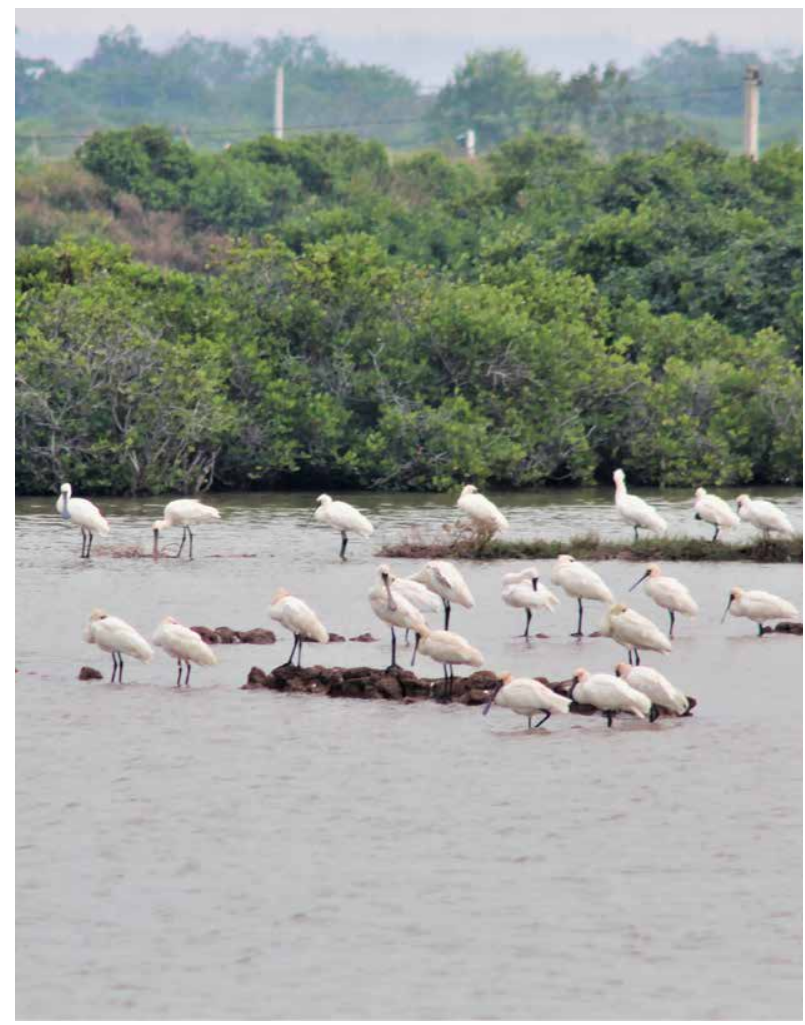

Cảnh quan sinh thái rừng ngập mặn ở Vườn Quốc Gia Xuân Thuỷ. Tác giả: Nguyễn Đức Tú/CIFOR

sách có liên quan; phỏng vấn 6 người cung cấp thông tin chính bao gồm quản lý cảng, bộ đội biên phòng và ban quản lý cảng; thảo luận nhóm tập trung gồm 8 người; và khảo sát hộ gia đình với 150 ngư dân và 8 đại diện tàu du lịch vào tháng 7 năm 2020. Chúng tôi cũng áp dụng Phương pháp Định giá Ngẫu nhiên (CVM). Phương pháp này CVM được sử dụng để định giá loại hàng hóa hay dịch vụ môi trường vốn không có thị trường (Halstead và cộng sự 1991). Các bảng câu hỏi được sử dụng để khơi gợi lựa chọn của cá nhân sẵn sàng bỏ ra một khoản tiền ra để làm thay đổi về số lượng hoặc chất lượng của hàng hóa hoặc dịch vụ phi thị trường. Phương pháp CVM được sử dụng rộng rãi để ước tính mức độ sẵn sàng chi trả của cộng đồng (WTP) cho các dịch vụ bảo tồn môi trường và hệ sinh thái (Alves và cộng sự2015; Brouwer và cộng sự 2016; Susilo và cộng sự 2017a; Trujillo và cộng sự 2016). Phương pháp này dựa trên giả định rằng tiền là tiêu chuẩn để đo lường giá trị. Sự chấp nhận của người tiêu dùng mô tả sự sẵn lòng hoặc khả năng nhận được số tiền đó của người tiêu 
dùng. CVM sử dụng kỹ thuật phỏng vấn trực tiếp đối với các cá nhân sống trong cộng đồng để thu thập thông tin về quan điểm của họ đối với sự thay đổi chất lượng nguồn tài nguyên. Đây là một dạng khảo sát thị trường khi các câu hỏi về mức độ sẵn lòng chi trả được đặt ra đối với việc cải thiện chất lượng dịch vụ môi trường. CVM cũng là một cách tiếp cận dựa trên khảo sát, trong đó một cá nhân tuyên bố một cách độc lập sự sẵn sàng chi trả (WTP) của mình cho việc bảo tồn các dịch vụ môi trường ở một địa điểm cụ thể (Mitchell và Carson1989).

Có hai loại câu hỏi chính về mức độ sẵn sàng chi trả (WTP): dạng câu hỏi trực tiếp hoặc câu hỏi mở và lựa chọn nhị phân (DC). Trong nghiên cứu này chúng tôi sử dụng phương pháp giới hạn đơn trong câu hỏi xác định WTP với 5 mức giá. Phương pháp này sẽ tránh được sự sai lệch trong các câu trả lời nhưng đòi hỏi xử lý thống kê phức tạp (Cooper và Loomis 1992). Chúng tôi sử dụng phương pháp lựa trọn nhị phân (DC) để ước tính WTP cho việc bảo vệ rừng ngập mặn ở thành phố Hải Phòng. DC bao gồm hai bước: đầu tiên sử dụng câu hỏi giới hạn đơn để đưa ra một câu hỏi là liệu mức giá được "chấp nhận" hay "bị từ chối" và sau đó sử dụng giới hạn hai chiều để đưa ra hai mức giá cho người trả lời. Trong phương pháp này, người được phỏng vấn sẽ được hỏi một câu hỏi "Có - Không" về việc họ sẵn lòng trả một khoản tiền nhất định cho mục đích bảo vệ rừng. Nếu họ trả lời "có" thì câu hỏi này sẽ được lặp lại với một số tiền lớn hơn, nếu họ trả lời "không" thì câu hỏi thứ hai sẽ hỏi với một khoản tiền nhỏ hơn. Điều này được lặp lại cho đến khi WTP cuối cùng được xác định. Ước tính WTP của người trả lời dựa trên câu trả lời có hoặc không cho từng câu hỏi ở năm mức giá khác nhau. Nếu người được phỏng vấn chấp nhận mức giá cho câu hỏi giới hạn đơn thì mô hình logit sẽ được áp dụng để lượng hóa giá trị WTP và các nhân tố ảnh hưởng đến WTP.

\section{Các loại dịch vụ môi trường rừng ngập mặn mà người sử dụng sẵn sàng chi trả tại Hải Phòng}

Hình 1 thể hiện quan điểm của các bên được phỏng vấn về tầm quan trọng của từng loại dịch vụ môi trường mà rừng ngập mặn cung cấp.

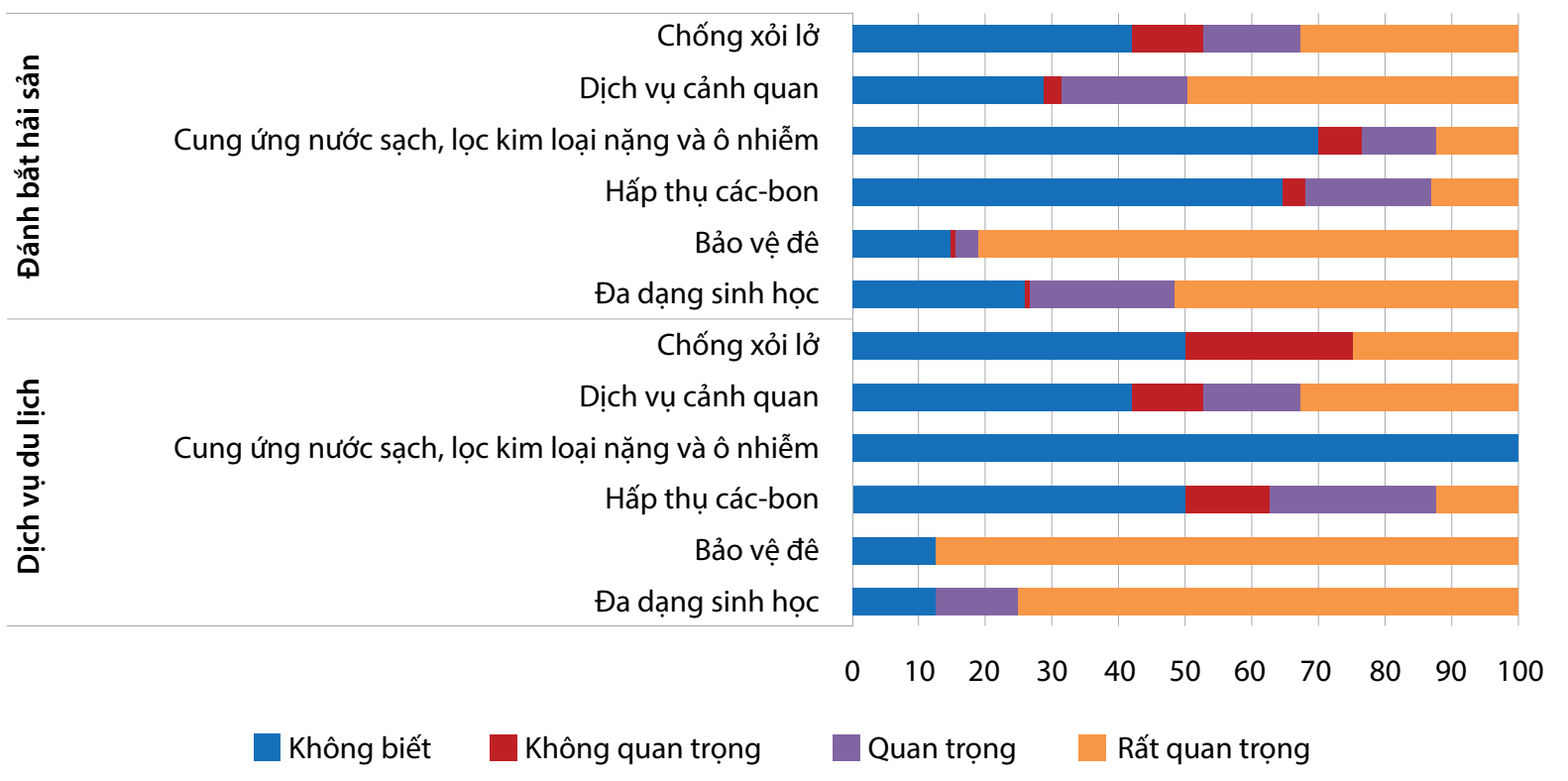

Hình 1. Quan điểm của người dân địa phương về các dịch vụ môi trường rừng ngập mặn cung cấp mà họ sắn sàng chi trả 
Bảng 1. Quan điểm của các bên liên quan về lý do họ chi trả cho bảo vệ rừng ngập mặn

\begin{tabular}{lcc}
\hline Lý do chi trả cho việc bảo vệ rừng ngập mặn & Tàu du lịch (\%) (n=5) & Tàu cá (\%) (n=102) \\
\hline Vẻ đẹp cảnh quan & 37.5 & 77.45 \\
\hline Bảo vệ môi trường, làm sạch nước & 12.5 & 20.59 \\
\hline Bảo vệ đê điều và sản xuất nông nghiệp & 50 & 63.73 \\
\hline Cung cấp củi và thức ăn & 0 & 26.47 \\
\hline Tăng thêm thu nhập cho người dân làm nghề cá & 37.5 & 63.73 \\
\hline Cho thế hệ tương lai & 12.5 & 81.37 \\
\hline Bảo vệ tuần thuyền khỏi gió bão & 12.5 & 10.78 \\
\hline
\end{tabular}

Lưu ý: Người trả lời có thể đưa ra nhiều lựa chọn

Trong số 150 ngư dân được khảo sát, chỉ 102 người trả lời (tương đương 68.0\%) sẵn sàng trả tiền bảo vệ rừng ngập mặn trong khi 5/8 (tương đương 62.5\%) tàu du lịch đồng ý trả tiền bảo vệ rừng ngập mặn. Nhìn chung, cả tàu du lịch và chủ tàu cá được phỏng vấn đều nhấn mạnh tầm quan trọng của rừng ngập mặn trong việc bảo tồn đa dạng sinh học, vẻ đẹp cảnh quan và bảo vệ đê điều. Điều này giải thích lý do tại sao những người được phỏng vấn sẵn sàng chi trả cho việc bảo vệ rừng ngập mặn (Bảng 1). Đa số những người cung cấp thông tin chính được phỏng vấn sẵn sàng trả tiền cho rừng ngập mặn vì họ muốn bảo vệ môi trường cho thế hệ tương lai (80.77\%); bảo vệ và gìn giữ vẻ đẹp cảnh quan (76.46\%), tăng thu nhập từ thủy sản (63.08\%) và bảo vệ đê điều phục vụ sản xuất nông nghiệp (62.82\%).

\section{Sự sẵn lòng chi trả của người sử dụng dịch vụ môi trường rừng ngập mặn}

6 cuộc phỏng vấn những người cung cấp thông tin chính và thảo luận nhóm tập trung với 8 người từ các cơ quan nhà nước, quản lý cảng, quản lý tàu thuyền du lịch và tàu cá đã được tiến hành để thảo luận về mức chi trả mà ngư dân và tàu du lịch có thể sẵn lòng chi trả. Kết quả của các cuộc phỏng vấn và kết quả thảo luận nhóm chỉ ra 5 mức chi trả mà tàu cá và tàu du lịch sẵn sàng trả (Hình 2). Tỷ lệ lựa chọn "đồng ý" cho mức chi trả (BD) dao động từ $64 \%$ cho $250,000-$ $68 \%$ cho $1,000,000$ đồng.

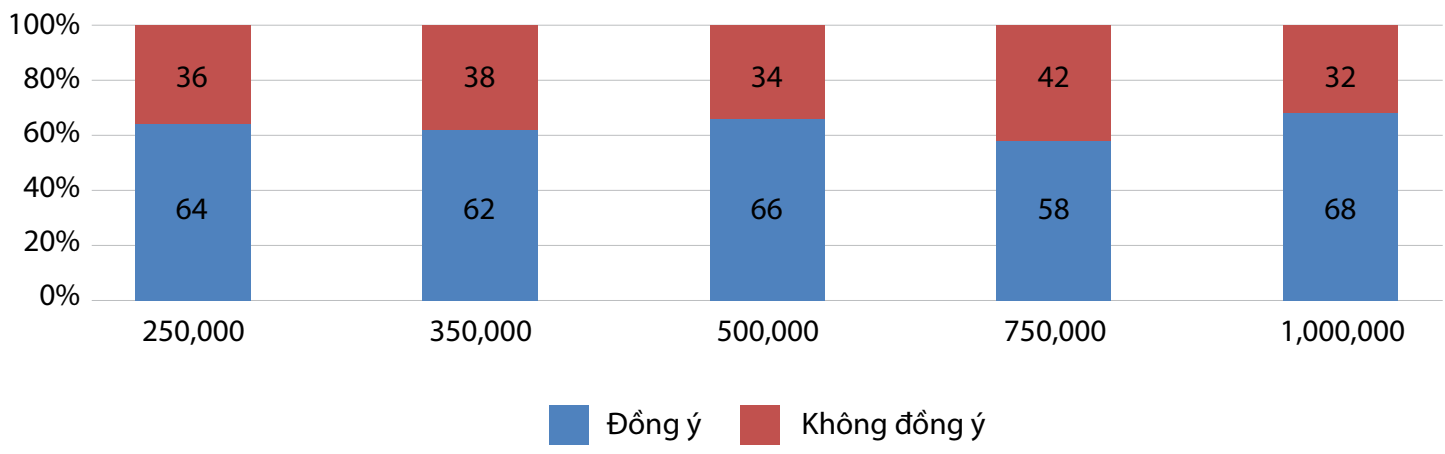

Hình 2. Tỷ lệ các số câu trả lời được lựa chọn theo mức chi trả 
Bảng 2. Các yếu tố ảnh hưởng tới mức sẵn lòng chi trả và mức chi trả

\begin{tabular}{lcccc}
\hline \multirow{2}{*}{ Hạng mục } & \multicolumn{2}{c}{ Tàu cá $(\mathrm{N}=150)$} & \multicolumn{2}{c}{ Tàu du lịch $(\mathrm{N}=\mathbf{8})$} \\
\cline { 2 - 5 } & $\begin{array}{c}\text { Đồng ý } \\
(\mathrm{N}=102)\end{array}$ & $\begin{array}{c}\text { Không đồng ý } \\
(\mathrm{N}=\mathbf{4 8})\end{array}$ & $\begin{array}{c}\text { Đồngý } \\
(\mathrm{N}=5)\end{array}$ & $\begin{array}{c}\text { Không đồng ý } \\
(\mathrm{N}=3)\end{array}$ \\
\hline Thu nhập (triệu đồng/tháng) & 30.54 & 16.06 & 19.0 & 6.16 \\
\hline Kinh nghiệm (năm) & 18.25 & 18.75 & 14.0 & 11.8 \\
\hline Phí cần phải trả (triệu đồng) & 0.22 & 0.265 & 0.64 & 0.53 \\
\hline Mức sắn sàng chi trả trung bình (triệu đồng/năm) & 0.58 & 0 & 0.45 & 0 \\
\hline
\end{tabular}

Trung bình, những ngư dân tàu cá được phỏng vấn sẵn lòng trả 0.58 triệu đồng/năm cho việc bảo vệ rừng ngập mặn trong khi tàu du lịch chỉ sẵn lòngtrả 0.45 triệu đồng/năm. Các tàu du lịch được phỏng vấn khẳng định rằng họ không sẵn sàng trả cao như tàu đánh cá vì thu nhập của họ thấp hơn do sự cạnh tranh cao giữa các tàu du lịch trong khu vực và chi phí cập cảng cao hơn. Cả hai nhóm đều phải trả phí cho ban quản lý cảng. Nhóm tàu cá trả phí cảng dưới 0.3 triệu đồng/năm trong khi nhóm du lịch phải trả gấp đôi so với ngư dân mỗi năm (Bảng 2). Bảng 2 cũng cho thấy rằng ngư dân được phỏng vấn có thu nhập trung bình cao hơn so với tàu du lịch được phỏng vấn.

\section{Thể chế chính sách tiềm năng cho chương trình PFES cho rừng ngập mặn}

\section{Thu như thế nào?}

Sommerville (2016) đã đề xuất xây dựng chương trình chi trả DVMTR cho các dịch vụ môi trường rừng ngập mặn thông qua hệ thống thu phí cảng hoặc thu phí qua cấp phép khai thác thủy hải sản. Theo phỏng vấn được tiến hành với ban quản lý cảng tại cảng Ngọc Hải, Hải Phòng cho thấy cả hai phương án này được cho là khả thi. Đối với ban quản lý cảng, điều này sẽ không làm tăng thêm chi phí cho họ. Hơn nữa, hồ sơ cho thấy cảng đang quản lý $83.37 \%$ tàu thuyền hoạt động trong khu vực, điều này có thể giảm chi phí hoạt động và chi phí giao dịch của hoạt động thu phí DVMTR nếu việc thu phí này do các cơ quan khác thực hiện. Tuy nhiên, ai nên thu phí và quản lý quỹ như thế nào mới là điều quan trọng hơn. Dựa trên cuộc thảo luận nhóm nhóm, việc thu phí DVMTR có thể thông qua cảng, bộ đội biên phòng hoặc chi cục thủy sản. Nhưng phần lớn các bên phỏng vấn cho rằng bộ đội biên phòng là lựa chọn phù hợp hơn tại Hải Phòng vì hiện tại bộ đội biên phòng có thể quản lý chính xác số lượng tàu thuyền bởi mỗi thuyết rời hoặc cập bảng phải được sự thông qua cấp phép của bộ đội biên phòng.

\section{Phân bổ như thế nào?}

Việc thiết kế chương trình chi trả DVMTR cho rừng ngập mặn không chỉ đòi hỏi một quy định rõ ràng về cách thu tiền chi trả mà còn phải quản lý và sử dụng tiền chi trả như thế nào. Thảo luận nhóm và phỏng vấn cho thấy cách thức chia sẻ lợi ích như Hình 3. Có đến $47 \%$ các bên liên quan được phỏng vấn cho rằng chi trả DVMTR nên được quản lý và sử dụng bởi chính quyền địa phương như chính quyền cấp xã hoặc cảng biển, $20 \%$ cho rằng tiền chi trả DVMTR sẽ giao cho đại diện cộng đồng hoặc hạt kiểm lâm quản lý việc phân bổ, $8 \%$ đồng ý rằng tiền chi trả DVMTR sẽ do chính

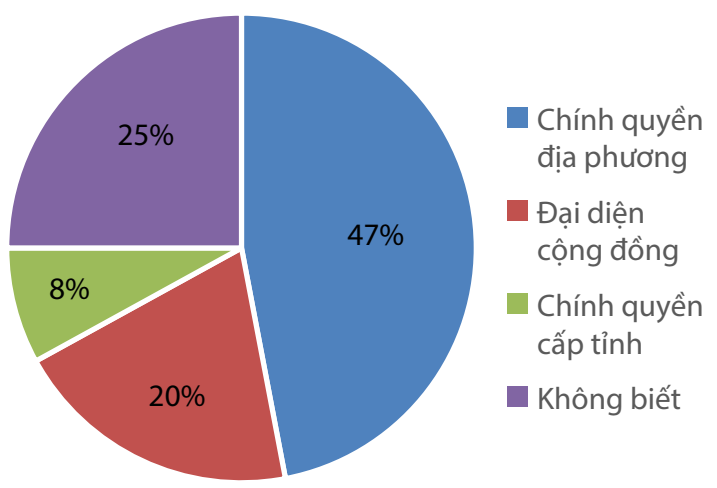

Hình 3. Quan điểm của địa phương về cách quản lý và phân bổ tiền chi trả DVMTR 
quyền cấp tỉnh quản lý, trong khi $25 \%$ các bên liên quan được phỏng vấn không rõ về cách quản lý và phân bổ tiền chi trả DVMTR (Hình 3).

\section{Mức chi trả sẽ được thiết lập thế nào?}

Kết quả phỏng vấn 11 người cung cấp thông tin bao gồm các nhà quản lý cảng và ban quản lý tàu đã đề xuất rằng mức chi trả có thể được thiết lập dựa trên chiều dài của thuyền. Một người quản lý cảng cho biết "Chúng tôi cần thiết lập một hệ thống dễ dàng để cảng có thể thu thập và giám sát việc chi trả DVMTR bằng cả giấy tờ và thực tế. Sẽ dễ dàng thu thập và giám sát việc chi trả vì thuyền được tô màu theo chiều dài của chúng". Cụ thể hơn, Điều 25, Thông tư 23/2018/ TT-BNNPTNT (15/11/2018) do Bộ Nông nghiệp và Phát triển Nông thôn ban hành quy định tàu thuyền được sơn theo kích cỡ để chính quyền địa phương quản lý (Bảng 3).

Bảng 3. Yêu cầu về chiều dài thuyền và khu vực đánh bắt

\begin{tabular}{lll}
\hline Chiều dài thuyền & Khu vực đánh bắt & Màu sắc \\
\hline Từ $6 \mathrm{~m}$ đến $12 \mathrm{~m}$ & Ven bờ & Xanh da trời \\
\hline Từ $12 \mathrm{~m}$ đến $15 \mathrm{~m}$ & Vùng lộng & Vàng \\
\hline Từ $15 \mathrm{~m}$ trở lên & Vùng khơi & Xám \\
\hline
\end{tabular}

Theo mô hình tuyến tính logit, kết quả cũng chỉ ra rằng biến chiều dài của thuyền là yếu tố quan trọng góp phần quyết định tàu cá sẽ đóng bao nhiêu tiền cho bảo vệ rừng ngập mặn. Hiệu ứng biên của biến này là dương và có ý nghĩa ở mức xác suất 5\% (Bảng 4). Điều này ngụ ý rằng những người đánh cá có thuyền lớn hơn có xu hướng trả tiền bảo vệ rừng cao hơn. Hệ số thay đổi chiều dài của thuyền chỉ ra rằng khi chiều dài tăng thêm một đơn vị thì xác suất người đánh cá tham gia đóng tiền bảo vệ rừng ngập mặn tăng thêm $4.7 \%$.

Mô hình hồi quy logit được phân tích đối với 150 tầu đánh bắt thủy sản. Kết quả được trình bày trong Bảng 4. Biến chi trả được nhận thấy là có ý nghĩa với hệ số âm (Coef $=-6.225, \mathrm{p}=0.000, \mathrm{t}=-3.5)$, chỉ ra rằng xác suất của người trả lời có bảo vệ rừng răng lên tăng khi mức giá chi trả giảm. WTP trung bình được ước tính là 1.37 triệu đồng (59 đô la Mỹ). Có mối tương quan tỷ lệ thuận giữa thu nhập của người trả lời và WTP để bảo vệ rừng ngập mặn (Coef $=0,08, p=0,006, t=2,77$ ).

\section{Kết luận}

Báo cáo này cho thấy phần lớn tàu cá và tàu du lịch được phỏng vấn sẵn sàng trả tiền để bảo vệ và phát triển rừng ngập mặn. Mức độ sẵn sàng chi trả của họ phụ thuộc vào các dịch vụ môi trường mà rừng ngập

Bảng 4. Các yếu tố quyết định sự sẵn sàng chi trả cho bảo vệ rừng ngập mặn

\begin{tabular}{lcccc}
\hline Biến & COEFFICIENT & Z-TEST & ME(dy/dx) & Z-Test \\
\hline intercept & -9.276 & -3.35 & & -2.49 \\
\hline BID & -6.225 & -3.5 & $-0.521^{* *}$ & -0.98 \\
\hline AGE & -0.043 & -1.02 & $-0.004^{\text {NS }}$ & 0.04 \\
\hline EDU & 0.004 & 0.04 & $0.000^{\text {NS }}$ & 0.02 \\
\hline GENDER & 0.018 & 0.02 & $0.002^{\text {Ns }}$ & 3.34 \\
\hline INCOME & 0.080 & 2.77 & $0.006^{* *}$ & 1.56 \\
\hline EXP & 0.070 & 1.63 & $0.005^{\text {NS }}$ & 2.65 \\
\hline Length of boat & 0.566 & 2.51 & $0.047^{*}$ & \\
\hline LR chi2(7) & 95.28 & & & \\
\hline Prob > chi2 & 0.000 & & & \\
\hline Pseudo R2 & 0.505 & & & \\
\hline Mean WTP (Mil.VND) & 1.376 & & & \\
\hline
\end{tabular}

Lưu ý: **, * có ý nghĩa tương ứng ở $1 \%, 5 \%$ mức xác suất ns: là không đáng kể; và $\mathrm{ME}$ là hiệu ứng biên 


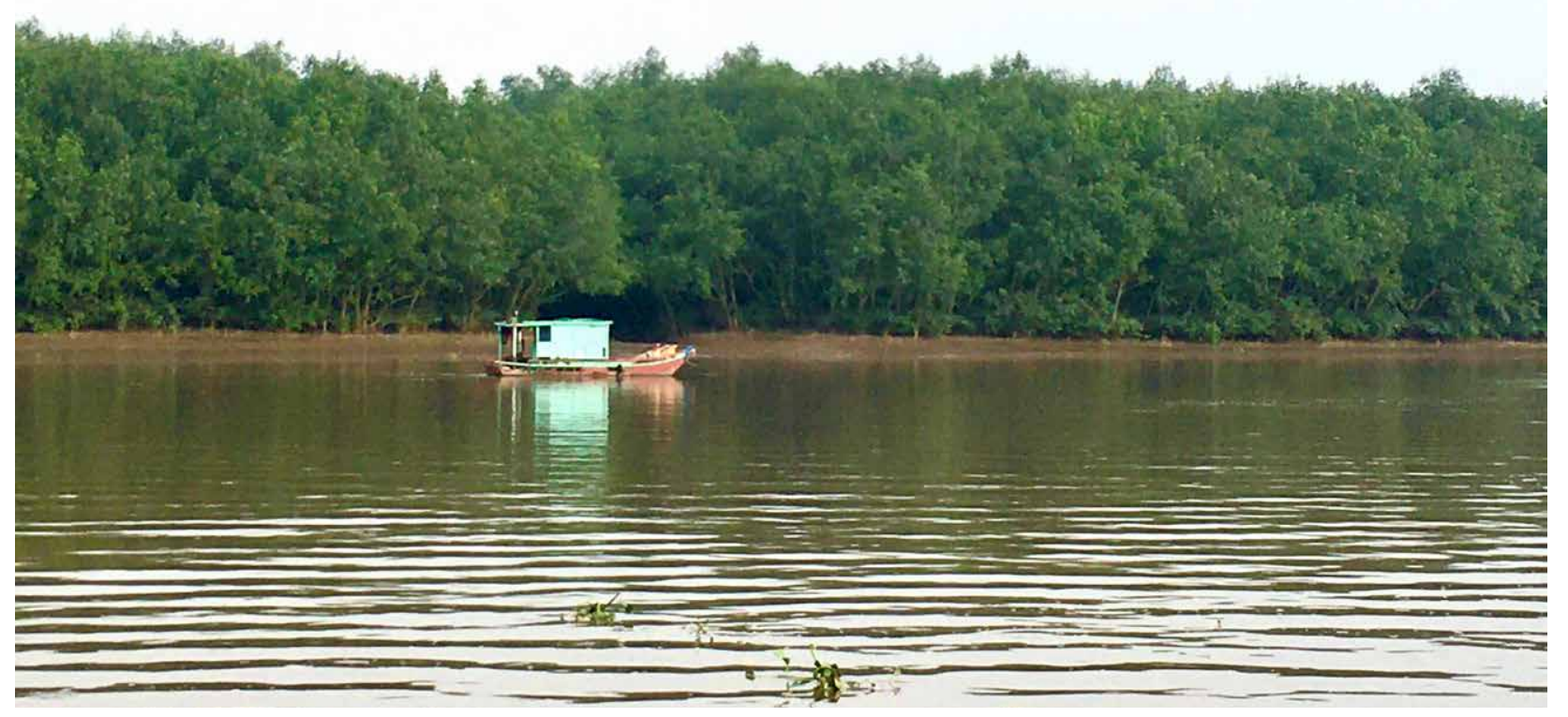

Sông Bạch Đằng tại thành phố Hải Phòng. Tác giả: Hoàng Tuấn Long/CIFOR

mặn cung cấp như vẻ đẹp cảnh quan, bảo vệ đê điều và bảo tồn đa dạng sinh học. Mức độ sẵn sàng chi trả của những người sử dụng dịch vụ môi trường này khác nhau giữa các nhóm và được quyết định bởi thu nhập hàng năm, chi phí hoạt động của họ và kích thước của thuyền mà họ sở hữu. Bản nghiên cứu tóm tắt này cũng cung cấp những ý tưởng ban đầu và sự đồng thuận của các bên liên quan tại Hải Phòng về cách thức thu tiền chi trả DVMTR thông qua hệ thống quản lý cảng và phí cập cảng với sự hỗ trợ của bộ đội biên phòng cùng như ý tưởng ban đầu về cách thức quản lý và phân bổ tiền chi trả DVMTR. Cần có thêm nhiều nghiên cứu ở các địa điểm khác của Việt Nam để cung cấp thêm bằng chứng về sự khả thi của chương trình này. Hơn nữa, việc nghiên cứu sâu hơn về mức độ sẵn sàng chi trả của các nhóm người sử dụng dịch vụ môi trường khác là cần thiết để thiết lập một chương trình chi trả DVMTR quốc gia áp dụng cho các nhóm người sử dụng dịch vụ môi trường khác nhau.

\section{Lời cảm ơn}

Chúng tôi xin cảm ơn các nhà tài trợ đã hỗ trợ nghiên cứu này, bao gồm Cơ quan Hợp tác Phát triển $\mathrm{Na}$ Uy (NORAD), Cơ quan Phát triển Hoa Kỳ (USAID) và Chương trình Nghiên cứu CGIAR về Rừng, Cây xanh và Nông lâm kết hợp (CRP-FTA).

\section{Tài liệu tham khảo}

Alves TM, Kokinou E, Zzodiatis G, Larder R, Panagiotakis C, Radhakrishnan H. 2015. Modelling of oil spills in confined maritime basins: The case for early response in the Eastern Mediterrannean Sea. Environ Pollut 206: 390-9.

Modelling of oil spills in confined maritime basins: The case for early response in the Eastern Mediterrannean Sea. Environ Pollut 206: 390-9. 
Brouwer H, Woodhill AJ, Hemmati M, Verhoosel KS. 2015. The MSP guide: how to design and facilitate multi-stakeholder parnerships. Wageningen UR:

Center of Development Innovation.

Chính phủ Việt Nam. 2010. Nghị định 99/2010/NĐ-CP chính sách chi trả dịch vụ môi trường rừng. Hà Nội, Việt Nam: chính phủ Việt Nam.

Cooper J and Loomis J. 1992. Sensitivity of Willingnessto -Pay to Bid Design in Dicohotomous Choice Contingent Valuation Models. Land Econemics 68: 211-224.

Halstead JM, Lindsay BF and Brown CM. 1991. Use of the Tobit Model in Contingent Valuation, Exerimental Evidence from the Pemigewasset Wilderness Area. Journal of Enviromentla Management 33: 79-89.

Mitchell RC, Carson RT. 1989. Using Surveys to Value Public Goods: The Contigent Caluation Method. Washington DC: Resources for the Future.
Phạm TT, Hoàng TL, Đào TLC, Ngô HC, Hoàng MH, Hoàng TU, Hoàng TT, Nông NKN, Nguyễn ĐT, Trương VV, Nguyễn TN. 2020. Dịch vụ và người mua dịch vụ môi trường rừng ngập mặn tiêm năng tại Việt Nam-kết quả từ nghiên cứu tại Hải Phòng. Info Brief số 287. Bogor, Indonesia: CIFOR.

Sommerville, M. (2016). Mangrove payment for environmental services in Vietnam: Opportunities \& challenges. Washington, DC: USAID Tenure and Global Climate Change Program.

Sulio H, Takahashi Y, Yabe M. 2017. Evidence for Mangrove Restoration in the Mahakam Delta, Indonesia, Based on Households' Willingness to Pay. Journal of Agricultural Science 9(3): 30.

VNFF. 2020. Tổng quan tác động chính sách chi trả dịch vụ môi trường rừng tại Việt Nam 2010- 2020 và định hướng 2021 - 2030. Hà Nội, Việt Nam.
RESEARCH PROGRAM ON

Forests, Trees and Agroforestry
Chương trình nghiên cứu của CGIAR về Rừng, Cây gỗ và Nông lâm kết hợp (FTA) là chương trình phát triển nghiên cứu lớn nhất thế giới nhằm nâng cao vai trò của rừng, cây gỗ và nông lâm kết hợp với mục tiêu phát triển bền vững và đảm bảo lương thực để ứng phó với biến đổi khí hậu. CIFOR chủ trì các nghiên cứu FTA trong mối quan hệ đối tác chiến lược với Bioversity International, CATIE, CIRAD, INBAR, ICRAF và TBI.

Nghiên cứu này được hỗ trợ bởi Quỹ đối tác CGIAR: cigar.org/funders/

\section{USAID}

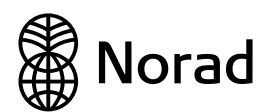

Federal Ministry

for the Environment, Nature Conservation and Nuclear Safety nghiên cứu sáng tạo, nâng cao năng lực của các bên đối tác, tích cực tham gia đối thoại với các bên liên quan để hỗ trợ định hình chính sách và thực tiễn tác động tới rừng và con người. CIFOR là tổ chức nghiên cứu thuộc liên minh CGIAR và chủ trì các chương trình nghiên cứu của CGIAR về Rừng, Cây gỗ và Nông lâm kết hợp (FTA). Trụ sở chính của CIFOR đặt tại Bogor, Indonesia và các văn phòng của CIFOR có mặt tại Nairobi, Kenya; Yaounde, Cameroon; Lima, Peru và Bonn, Germany. 